Keywords:

Murphy's test:

Acute cholecystitis;

Gallbladder disease
Reprint Requests:

Steven H. Yale, MD, FACP

Department of Internal Medicine

Marshfield Clinic

1000 North Oak Avenue

Marshfield, WI 54449

Tel: $715-387-5436$

Fax: 7|5-389-3808

Email:yale.steven@mcrf.mfldclin.edu

\section{John Benjamin Murphy (1857 - 1916)}

Kenneth Musana, MD and Steven H. Yale, MD
A male, 45 years of age, presents to the emergency room with complaints of fever and right upper quadrant abdominal pain. Could this patient have acute cholecystitis? How will you confirm your suspected diagnosis?

Acute cholecystitis can be suspected in patients with a history of fever and right upper quadrant abdominal pain. Clinical examination often reveals fever, jaundice (often very subtle), and right upper quadrant tenderness. If pain with inspiratory arrest occurs when the inflamed gallbladder comes into contact with the examiner's hand, the patient has a positive Murphy's sign.

Dr. John Benjamin Murphy (figure 1) will be best remembered for this clinical sign that is used in evaluating patients with acute cholecystitis. Other eponyms associated with him include Murphy drip, Murphy's button, Murphy's punch, Murphy's test, and Murphy-Lane bone skid. ${ }^{1}$ His other pioneering works include performance of end-to-end anastomosis of hollow viscera, early surgical intervention in cases of appendicitis, use of pneumothorax to treat pulmonary tuberculosis, surgical intervention for prostate cancer, and reconstruction of ankylosed joints. His career spanned the fields of general surgery, orthopedics, neurosurgery, and cardiothoracic surgery gaining international prominence in the surgical profession. William J. Mayo described him as "the surgical genius of our generation." 2

John Benjamin Murphy was born of Irish immigrant parents on a farm in Appleton, Wisconsin on December 21, 1857. ${ }^{3}$ His parents had immigrated to the United States to escape the scourge of the potato blight in Europe.

Murphy was a very eager and hardworking student. He graduated from Appleton High School in 1876 and from Rush Medical College in 1879 at 22 years of age. Unlike many of his counterparts of that era, Murphy enrolled in an 18-month internship at Cook County Hospital (Illinois), practiced for a few years, and decided to go to Europe in 1882 for 2 years of further studies. While in Europe, he studied under prominent surgeons including Dr. Theodor Billroth. 


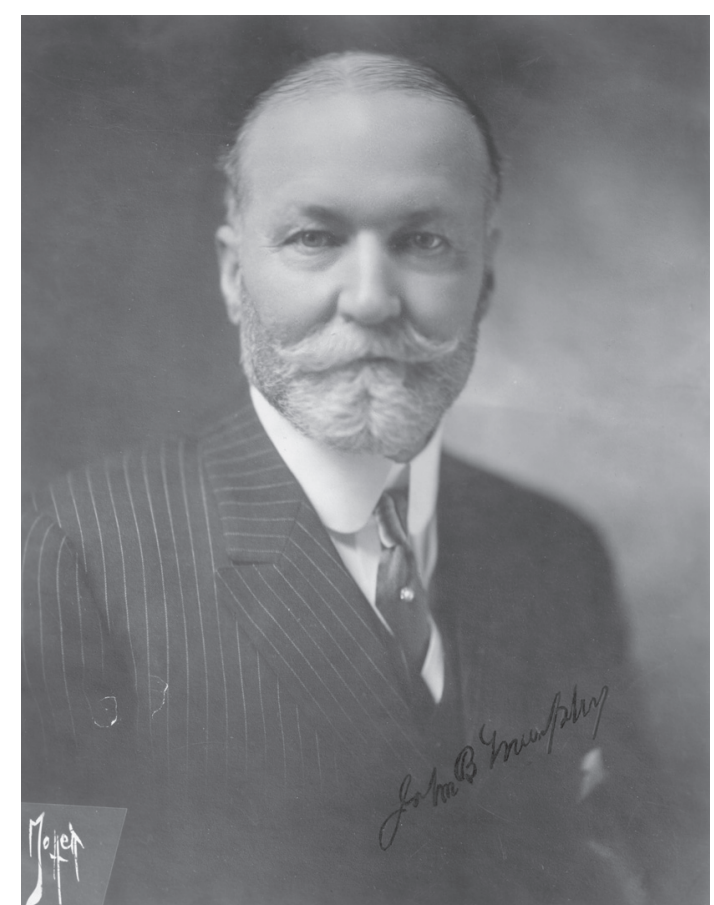

Figure 1. John Benjamin Murphy, MD. Photo by Moffett Studio. Reprinted with permission by the American College of Surgeons.

In 1889, Murphy advocated for early surgery in the treatment of appendicitis to prevent complications. He performed one of the first operations in early acute appendicitis, ${ }^{4}$ but his initial presentation to the Chicago Medical Society was met with much skepticism. Realizing this, he set out to document his cases and collected more than 250 cases over 4 years. During that time many physicians advocated conservative management of cases of appendicitis, and his recommendations for early surgery were met with considerable resistance until he was able to present his case records. When he next appeared before the Chicago Medical Society, he spoke with authority on this subject. Working far beyond his era, Murphy practiced evidence-based medicine.

In 1892, at the age of 35, Murphy designed Murphy's button that, in his own words, "...would revolutionalize intestinal surgery". ${ }^{5}$ Murphy's button is a mechanical device that allows approximation of hollow viscera without sutures. Though another surgeon had described a similar device, Murphy improved on the design, demonstrated its efficacy, and cleared the way for successful cholecystectomies. He first tested the device on a dog; later reporting on his animal experiments and human operations in a December 1892 article entitled "Cholecysto-intestinal, gastro-intestinal, entero-intestinal anastomosis and approximation without sutures." ${ }^{\prime}$

Murphy's interests spanned a variety of surgical fields. In 1897, he published an article on end-to-end anastomosis of vessels ${ }^{7}$ that was the pioneering work in the field of vascular surgery. He also promoted the treatment of pulmonary tuberculosis with injection of nitrogen into the pleural cavity to compress the lung, which he described as "therapeutic pneumothorax." ${ }^{5} \mathrm{He}$ introduced the method of saline infusion per rectum for the treatment of peritonitis, ${ }^{8}$ pioneered the use of local anesthesia in surgery of the lung, ${ }^{9}$ and also showed an interest in neurosurgery by studying surgery of the spinal cord and the peripheral nerves. ${ }^{10}$

At Mercy Hospital in Chicago, Murphy conducted "wet clinics" in which he operated and taught in front of an audience. These clinics were very popular and attracted physicians from throughout the United States, as well as from Canada and some foreign countries. In order to disseminate his presentations to a wider audience, he started the publication, The Surgical Clinics of John B. Murphy, M.D., at Mercy Hospital, Chicago. This publication formed the basis for The Surgical Clinics of Chicago, which were later named The Surgical Clinics of North America. ${ }^{11}$

Some considered Murphy's approach to medicine to be overly pretentious. In fact, his work was more highly regarded and accepted in Europe than in Chicago. Murphy died on August 11, 1916 on Mackinac Island, Michigan of aortitis after suffering from angina. Two days prior to his death he had written, "I think the necropsy will show plaques in my aorta" and, indeed, this was later confirmed at autopsy. ${ }^{5}$

\section{Efficacy of Murphy's Sign}

Murphy's sign is elicited in patients with acute cholecystitis by asking the patient to take in and hold a deep breath while palpating the right subcostal area. If pain occurs when the inflamed gallbladder comes into contact with the examiner's hand, Murphy's sign is positive.

To assess the ability of various clinical and laboratory parameters to predict the results of hepatobiliary scintigraphy (HBS) in patients with suspected acute cholecystitis, Singer and colleagues ${ }^{11}$ conducted a retrospective study among 100 consecutive patients who underwent HBS. The presence of Murphy's sign was both sensitive (97.2\%) and highly predictive $(93.3 \%)$ of a positive HBS in this group of patients. However, Adedeji and McAdam ${ }^{12}$ demonstrated that Murphy's sign is not as reliable in elderly patients. They retrospectively investigated how the presence or absence of Murphy's sign affected the initial diagnosis of acute cholecystitis in elderly patients ( $>70$ years of age) and found that in the presence of Murphy's sign, diagnostic accuracy for acute cholecystitis was $80 \%$ and dropped to $34 \%$ when the sign was negative. The positive predictive value of the test in the same patients was $58 \%$, with a sensitivity of $48 \%$ and a specificity of $79 \%$. Adedeji and McAdam concluded that in elderly patients a positive Murphy's sign is useful, but a negative sign should be treated with caution and other diagnostic tests should be conducted.

In an attempt to determine if aspects of the history and physical examination or basic laboratory testing could clearly identify patients requiring diagnostic imaging tests to confirm or exclude the diagnosis of acute cholecystitis, 
Trowbridge and colleagues ${ }^{13}$ performed a Cochrane review of 17 studies. They found that no single clinical or laboratory finding had a sufficiently high positive likelihood ratio (LR) or low negative LR to confirm or exclude the diagnosis of acute cholecystitis. Possible exceptions identified were Murphy's sign (positive LR: 2.8; 95\% confidence interval (CI): 0.8 to 8.6 ) and right upper quadrant tenderness (negative LR: $0.4 ; 95 \% \mathrm{CI}: 0.2$ to 1.1 ). However, the $95 \% \mathrm{CIs}$ for both included 1.0. Thus, further objective diagnostic imaging with ultrasonography or computerized tomography (CT) is required to confirm the diagnosis of acute cholecystitis. CT examination of the abdomen is considered the diagnostic modality of choice, particularly if there is suspicion of complications such as perforation of the gallbladder.

\section{Ultrasonography in Gallbladder Disease}

Ultrasonography has become the diagnostic imaging study of choice in gallbladder disease. It can routinely detect gallstones as small as $2 \mathrm{~mm}$ in diameter; the overall sensitivity of ultrasound scanning for gallstones larger than 2 $\mathrm{mm}$ in diameter is greater than $95 \% .{ }^{14}$ Ultrasonography also has utility in the diagnosis of acute cholecystitis in which pericholecystic fluid (in the absence of ascites) and thickening of the gallbladder wall beyond $4 \mathrm{~mm}$ (in the absence of hypoalbuminemia) are nonspecific findings suggestive of the disease. It has an adjusted sensitivity and specificity for the diagnosis of acute cholecystitis of $88 \%$ (95\% CI: 0.74 to 1.00$)$ and $80 \%$ (95\% CI: 0.62 to 0.98$)$, respectively. ${ }^{14}$

Focal tenderness over the gallbladder caused by the ultrasound transducer during imaging, also referred to as an ultrasonographic Murphy's sign, has a positive predictive value $>90 \%$ for detecting acute cholecystitis if gallstones are present. This, however, requires an alert patient and a skilled operator. Moreover, a positive ultrasonographic Murphy's sign is present only when tenderness is maximal over the sonographically localized gallbladder. In a review of 497 consecutive patients evaluated for suspected acute cholecystitis, Ralls and colleagues ${ }^{15}$ found that $98.8 \%$ of the patients in their series had a positive ultrasonographic Murphy's sign, making it a useful diagnostic test. They demonstrated that a combination of gallstones and a positive Murphy's sign had a positive predictive value of $92.2 \%$ for acute cholecystitis, while the absence of gallstones together with a negative Murphy's sign had a 95\% negative predictive value. ${ }^{15}$ Despite being a reliable predictor of acute cholecystitis in the appropriate clinical setting, a patient with a positive Murphy's sign needs to be further evaluated with an imaging study, preferably ultrasonography.

Palpating the abdomen of a patient who complains of fever and right upper quadrant abdominal pain will elicit a positive Murphy's sign if the patient has an inflamed gallbladder. You can thank Dr. John Benjamin Murphy for developing the technique that helped to confirm your suspected diagnosis of acute cholecystitis.

\section{References}

1. John Benjamin Murphy. Available at: http://www.whonamedit.com/doctor.cfm/1981.html. Accessed January 19, 2005.

2. Rutkow IM. A history of The Surgical Clinics of North America. Surg Clin North Am 1987;67:1217-1239.

3. Deaths. JAMA 1916;67:629.

4. Murphy JB. Early treatment of perityphlitis. West Med Rep 1889;11:282-291.

5. Davis L. J.B. Murphy. Stormy petrel of surgery. New York, NY: GP Putnam's Sons; 1938.

6. Murphy JB. Cholecysto-intestinal, gastro-intestinal, entero-intestinal anastomosis, and approximation without sutures. Med Rec (NY) 1892;42:665-676.

7. Murphy JB. Resection of arteries and veins injured in continuity - end to end suture - experimental and clinical research. Med Rec (NY) 1897;51:73-88.

8. Murphy JB. Proctoclysis in the treatment of peritonitis. JAMA 1909;52:1248-1250.

9. Murphy FT. The choice of anesthetic in operating for abscess of the lung: a report of two cases operated upon under local anesthesia. Ann Surg 1914;60:36-41.

10. Murphy JB. Neurological surgery. Surg Gynecol Obstet 1907;4:385-500.

11. Singer AJ, McCracken G, Henry MC, Thode HC Jr, Cabahug CJ. Correlation among clinical, laboratory, and hepatobiliary scanning findings in patients with suspected acute cholecystitis. Ann Emerg Med 1996;28:267-272.

12. Adedeji OA, McAdam WA. Murphy's sign, acute cholecystitis and elderly people. J R Coll Surg Edinb 1996;41:88-89.

13. Trowbridge RL, Rutkowski NK, Shojania KG. Does this patient have acute cholecystitis? JAMA 2003;289:80-86.

14. Shea JA, Berlin JA, Escarce JJ, Clarke JR, Kinosian BP, Cabana MD, Tsai WW, Horangic N, Malet PF, Schwartz JS, Williams SV. Revised estimates of diagnostic test sensitivity and specificity in suspected biliary tract disease. Arch Intern Med 1994;154:2573-2581.

15. Ralls PW, Colletti PM, Lapin SA, Chandrasoma P, Boswell WD Jr, Ngo C, Radin DR, Halls JM. Real-time sonography in suspected acute cholecystitis. Prospective evaluation of primary and secondary signs. Radiology 1985;155:767-771.

\section{Author Affiliations}

Kenneth Musana, MD, Department of Internal Medicine, Marshfield Clinic, 1000 N. Oak Avenue, Marshfield, Wisconsin 54449.

Steven H. Yale, MD, FACP, Clinical Research Center, Marshfield Clinic Research Foundation and Department of Internal Medicine, Marshfield Clinic, 1000 N. Oak Avenue, Marshfield, Wisconsin 54449. 